\title{
Study of the Second Language Acquisition and Its Bilingualism
}

\author{
Wenping $\mathrm{Fu}^{1}$ \\ Xi'an Iternational University, Xi'an, Shaanxi, 710077 \\ a email
}

KEYWORDS: Second language; Bilingualism; Bilingual Education

\begin{abstract}
Our bilingualism mainly minority concentrated residential areas, bilingualism four multi-ethnic environment heteropolymeric district, a few foreign immigrants living area and bilingual families under, and bilingualism correspond to the presence of our national language and Chinese, Western and Chinese, Chinese and foreign language bilingual education. Judging from the destination, second language acquisition is to train bilingual personnel services. Judging from the condition, bilingual teaching can promote second language acquisition, analysis bilingualism in favor of Second Language Acquisition.
\end{abstract}

\section{Introduction}

After the economic globalization, China and strengthen foreign exchange, foreign exchange increasing requirements of the 21st century personnel should have at least one foreign language, becoming bilingual or multilingual person [1]. While the government vigorously promote Putonghua, and our nation are complicated, many languages, bilingual education has become an inevitable requirement of education. Our theory of bilingualism and bilingual education is not thorough research on bilingualism and bilingual education concepts and categories are not clear, the impact of second language acquisition effect. Therefore, the analysis of our bilingualism, bilingual education from the perspective of education of second language acquisition, bilingual education principles put forward to promote second language acquisition.

\section{Chinese Bilingualism}

Bilingualism refers to a certain state, nation or region, according to communication needs of the two languages used interchangeably phenomenon, both languages are native and non-native [2]. Our nation is numerous, complex language. In addition to the Chinese, there are more than 50 kinds of minority languages. In addition, the deepening of China's foreign exchange, foreign language use more frequently. Overall, China's bilingualism is divided into four.

Bilingualism First Ghetto. Bilingualism in the region mainly Chinese-speaking and bilingual, our national policy, while allowing minorities to use their native language, but the policy of compulsory education system and students in the same environment, education, compulsory education students in minority areas inevitably become a dual language users. Moreover, parts of the country requires greater use of Chinese ethnic minority children. Guangxi Zhuang Autonomous Region to our students, for example, only students before admission to master language, the vast majority of Chinese students to master the native language and two languages, there are a large number of students to master the language, Chinese and Yao three languages. Daily family and social life, 
students are mainly native language daily interactions. Living in student learning, students use the Chinese language more frequently;

Second, much bilingualism multiethnic areas. Multi-ethnic mixed area students to master a second language, and second language belongs to the main language of daily communication and exchange, and the second language has been initially mastered in preschool. And after entering the school to receive formal education, second language to further accelerate the pace of development, it has become a second language students than the essential terms. The second language may be Chinese, it may be in another language other than Chinese;

Third bilingualism immigration area. Daily life, immigrant area residents mainly use their mother tongue communication, non-verbal homologous immigrant children may use a common language in their social life area. However, immigrants need to adapt to life and moved to meet social communication, immigrant residents need to learn Chinese, and became the mother tongue and Chinese bilingual users, some students even become more language users, students master a second language faster than parents fast, but also a deeper mastery [3];

Fourth bilingualism bilingual family. In most foreign families, families of students belong to the dual language users. Students born after a long period of dual language environment, parents use multilingual communication with students, before entering school and society has become stable dual language users. In general, the language used by parents of students belonging to the mother tongue. In another part of the family, the higher level of foreign language parents, parents conscious of the double language and student exchanges, students become bilingual early users.

As it can be seen from the type of bilingualism, bilingual students at different types of bilingualism in an unbalanced state. The first class of students the chance to receive formal education prior to contact with the second language is less, the main language of instruction as a second language, it may be up. The class basis of poor students in a second language, bilingual balance with daily life and school learning to use the language of the relevant frequencies. The second and third class of students belonging to a single language family long-term, second language acquisition late, but the second language is the student's major daily communication language, and school to further strengthen the second language, so that the second and third category second language students a solid foundation, firmly. The fourth class of students to obtain an earlier contact with the second language, first and second language almost simultaneous contact, thus such students can better grasp simultaneously the first and second language skills and habits. When the language habits are properly reinforced, students can master two languages are completely balanced.

\section{Analysis of the Effect of bilingualism on Second Language Acquisition}

Bilingualism can be seen from the analysis, the student's second language acquisition situations with students' bilingual environment are closely related, and primarily through a pair of second language acquisition following an impact role.

Including all aspects of a specific locale student life, study the text referred to the specific environment of the family, school exchanges and three specific environment. The exchanges and the school environment, students use different languages to communicate, student input and output in two different languages at the same time, students will naturally become double language users, students' second language acquisition will greatly enhance the efficiency of [4]. Instead, students in under long-term single-language environment, both sharing and learning the mother tongue, students in Second Language Acquisition efficiency will be greatly reduced, even if the students spend a lot of time in learning a second language, students also difficult to become bilingual. 
Admittedly, long-term effort to improve student learning writing, translation and reading skills, and get some skills, but students are still unable to reach the level of spoken English bilingual standards. And at home longer young student activity time, influenced by the family environment, therefore the family environment of low lead students' vital second language acquisition. As a bilingual family students, even students of the school environment in which a single locale, such students are still good enough to become bilingual.

In general, students master the native language of the difficulty of less than a second language, the main opportunities for students to practice using up far more than a second language. In a good language environment, native also more likely to become a student of the dominant language, second language play only secondary roles term. However, in exceptional circumstances, a second language can also be a student of the dominant language. When students away up the environment, and into the second language environment, opportunities for students to use a second language than mother tongue, the role of the mother tongue and second language exchange, language status of different changes occur.

Most psychologists and linguists pass on the best time to start learning the language a lot of research, but has not yet formed a unified conclusion, but all studies agree that there is a critical period of language learning. The critical period, the students learned the most efficient second language; after the critical period, second language acquisition more difficult, the effect is reduced. The result has also been confirmed by a large number of experiments. Generally speaking, the best time to learn a language student from 2 to 5 years old, children can easily grasp the number of languages, thus students in family life can be earlier contact with the second language, students can easily master the two languages.

For the second and third class of students in bilingual phenomenon, they become the key lies in greater society bilingual communication for second language requirements. If the student does not have a second language, student learning and life will be greatly affected. It is also a high social demand for second language students take the initiative to promote second language acquisition. In addition, social attitudes also affect second language students in Second Language Acquisition factor. For students in the ghettos and bilingual families, the surroundings, although the demand for second language is not high, but from a long-term perspective, a second language to students and future work brought great convenience [ 5]. To some extent, the role of second language higher up, so this environment parents consciously create a bilingual environment to help students better second language acquisition. In such cases, second language acquisition and learning through in two ways, learning the proportion may be higher than the acquisition mode.

\section{Bilingual Second Language Acquisition Strategy}

Bilingual education must meet certain requirements for second language proficiency, bilingual education but not in this final expectations, but the focus is to highlight the following three purposes. First, the purpose of social needs. Second language education should meet the social and cultural requirements, and use the second language to solve specific problems, the promotion of social, ethnic integration. As in the first and second category of students second language education should meet the needs of national and international exchanges, promote national and national development, preservation of ethnic traditions text. At the same time, we should also meet the social demand for talent. Strengthen international cooperation to promote talent must master a language of communication [6]. Therefore, the current second language education need to focus on the requirements of social development. Second, the purpose of personal development. Second language education students need to follow the law of development, and promote physical and 
mental development of students through scientific intervention, the maximum tap their potential. Third, academic development purposes. Academic development goals including the purpose and professional purpose language, second language education have received two languages should be promoted to improve and promote each other.

Language is the carrier of culture, are outside the explicit cultural expressions. Successful education and second language acquisition students to master the language is closely related to culture representatives. So that the second language acquisition education, not only need to consider the structural characteristics of the language itself, but also need to guide students to master a second language culture, language produce cultural identity. In language education, age characteristics need to arrange the object of education and cultural order. Child Students should first pay attention to the first language education, then contact the second language education. Based on this level is the successful second language acquisition should also coordinated and complementary educational and cultural values of pluralistic tolerance of two cultures.

Based on the key factors of language and nonverbal learning, preschool can be introduced into a second language. Preschool children lacking social experience, are there any new things extremely open and receptive. Students have little life experience to influence students' second language acquisition for preschool children in Second Language Acquisition provides a good external environment. In addition, the benefits of early introduction of the second language acquisition lies less education student limit, students are not afraid to make mistakes, and more willing to use a second language and a second language as a kind of interesting games. However, due to the physical and mental development of young students' immaturity, the student's second language acquisition phase educational goals should not be too high, and should be of interest to focus on students and education through practical way, and then gradually the introduction of curriculum system.

Acquisition is the subconscious and the process of obtaining informal learning belongs conscious and formal acquisition process, we can see from our bilingualism, students master the language, not just a mechanical process of imitation, more contact in an informal language environment after contacting the inner language of form, creatively completed. But in this case the palm of students obtain a second language has a formal way, but with great volatility, requires students to pay a lot of effort [7]. Therefore, we need to informally as a supplement to mobilize students' emotion and motivation, will enter into active passive absorption, so that students are free to have the opportunity to use a second language, and gradually learned a second language.

\section{REFERENCE:}

[1] Ma Fengming. Bilingual Teaching Second Language Acquisition Effect [J]. China Science and Technology Information, 2010,02: $230+232$.

[2] Sun Xiaohong. Krashen Second Language Acquisition Theory Analysis of Bilingual Teaching Mode Suitable for China [J]. Exam Week, 2009,44: 103-104.

[3] Xie Li. On Bilingualism, Translation and Professional Translation [J] Everyone, 2010,17: 230.

[4] Sun Wenfang. Acquisition of A Second Language Based on the Language Typology [J]. Language Teaching And Research, 2012,02: 1-8.

[5] Jiang Wenping. Second Language Acquisition Language Transfer [J]. Science and Technology Information, 2012,14: 141.

[6] Xuxing Chun, Hu Yue. Foreign Children Second Language Acquisition Review and Prospect [J]. Chinese Special Education, 2014,07: 91-96. 
[7] Peng Hui. Chines Bilingual Phenomenon [J]. Science Mass (Science Education), 2015,08: 136 + 94 . 